\title{
Item Response Rates for Composite Variables
}

\author{
Jonathan Eggleston ${ }^{1}$
}

\begin{abstract}
Item response rates frequently serve as indicators of data quality and potential nonresponse bias. However, key variables from surveys, such as total household income or net worth, are often composite variables constructed from several underlying components. Because such composite variables do not have clearly identifiable response rates, inference on the data quality of these key measures is more difficult. This article proposes three new methods for aggregating data on response rates across questions to create a measure of item response for composite variables. To compare the three methods and illustrate how they can be used (both individually and collectively) to investigate data quality, I analyze item response for net worth in the Survey of Income and Program Participation (SIPP) and the Survey of Consumer Finances (SCF). These new measures provide detailed information about net worth estimates that would be difficult to assess without an item response aggregation method. Overall, these new item response rate methods provide a new way of describing data quality for key measures in surveys and for analyzing changes in data quality over time.
\end{abstract}

Key words: Response rates; nonresponse.

\section{Introduction}

Unit and item response rates are widely used tools in survey research to measure the potential impact of nonresponse bias (e.g., Bollinger et al. 2015). While low response rates do not necessarily lead to high nonresponse bias (Groves and Peytcheva 2008), constructing an alternative measure based on validation studies is often difficult or infeasible for many surveys. For example, evaluating nonresponse bias in wealth data from the United States is extremely difficult because the United States lacks comprehensive administrative data on wealth, due to the absence of a wealth tax. Because of this absence of validation data, response rates are seen as one of the primary indicators of data quality, and are sometimes the only indicator available.

Considerable attention has been focused on how to construct unit response rates properly (e.g., American Association for Public Opinion Research 2016), analyzing item response rates for individual survey questions (e.g., Ferber 1966), and studying nonresponse bias for some topics in which administrative data is available (e.g., Bound and Krueger 1991 for earnings; Bee and Mitchell 2017 for retirement income). However, little attention has been given to item response rates for composite variables that are created from several survey questions, despite the fact that these composite variables are

${ }^{1}$ U.S. Census Bureau, 4600 Silver Hill Road, Washington DC, 20233, U.S.A. Email: Jonathan.S.Eggleston@census.gov

Acknowledgments: The views expressed are those of the author and not necessarily those of the U.S. Census Bureau. 
often the key measures in surveys and receive the most attention. Such variables are also called recode or summary variables. Examples of such variables include net worth from the Survey of Income and Program Participation (SIPP) and the Survey of Consumer Finances (SCF), employment status from the Current Population Survey (CPS), and household income from the CPS Annual Social and Economic Supplement.

While item response rates are available for the underlying components, this information may be hard for data users to synthesize. The SCF, for example, has over 140 assets and liabilities questions, and response rates can vary substantially across questions. For example, the question on home value in the $2013 \mathrm{SCF}$ has an item response rate of $90.6 \%$, while the question on the cash value of life insurance has a response rate of only $58.9 \%$. Without aggregating the response rates in a meaningful way, it is extremely difficult to assess how key estimates from these surveys are impacted by item nonresponse.

Because researchers often look at response rates to gauge data quality, having such information for composite variables could be useful for individuals evaluating the trustworthiness of key estimates, evaluating the effects of a major survey redesign, or deciding upon which dataset to use for a research project. To the best of my knowledge, there has been no paper that focuses on how to construct item nonresponse rates for composite variables. In a paper on item nonresponse bias, Hokayem et al. (2017) briefly describe total item response rates for household income in the CPS Annual Social and Economic Supplement. However, their paper is not focused on item response rate calculations, nor do they discuss alternative ways of constructing such a measure.

This article proposes several new methods for aggregating data on response rates across questions to create a measure of item response for composite variables. These methods provide a useful way to summarize item response rates for key measures, and offer a feasible way of comparing item response rates across surveys and over time. The three proposed measures of response rates are

1. The percent of observations without any missing component,

2. A sum-weighted formula, which is the sum of reported values divided by the sum of all values, and

3. A median-weighted formula, in which the response rate for each question is weighted by the percent of respondents with a non-missing/non-zero value times the median value.

I present three methods instead of just one for several purposes. First, there is no single "correct" way to construct response rates, so some users may have a preference for one over the other. Second, it is useful to present the comparisons across surveys using multiple methods as a robustness check, in order to make sure that the relative differences in response rates between surveys is not solely due to idiosyncratic features of one composite rate formula. Third, one formula may be preferable over the other depending on the key statistic or composite variable of interest. Some factors to take into consideration are

- How many variables are used to construct the composite variable,

- The type of key statistic of interest (e.g., mean vs. median),

- Differences in response rates across questions, and

- Relative importance of each variable for the key statistic. 
For example, if the key statistic is composed from only a few items, such the Positive and Negative Affect Schedule (PANAS), (Watson et al. 1998) or disability indicators in US surveys, then Method \#1 may be sufficient. However, if the key statistic is composed of over 100 items, then Method \#1 may give a misleading picture of the prevalence of item nonresponse, as someone would be coded as an item nonresponder even if they failed to answer just one question. For income and wealth statistics, Method \#2 may be more useful if the key statistic is total wealth or income for the country, while Method \#3 may be more useful for analyzing medians. Thus, similar to the numerous AAPOR unit response rate calculations (American Association for Public Opinion Research (AAPOR) 2016), presenting multiple formulas can help accommodate researchers who may have varying needs or reasons for using one method over another.

To illustrate these methods, I focus on the key estimates of household wealth in the United States (e.g., mean, median, total), which are available from the SIPP and the SCF. Within an individual survey, the three proposed formulas yield different answers for the level of item nonresponse. For example, when looking at all assets and debt in 2014 SIPP, only $27.7 \%$ of households have no imputed asset or debt value (Method \#1). However, when using the median-weighted formula (Method \#3), asset and debt questions have an average response rate of $77.3 \%$. This discrepancy is driven by the fact that home values have a high response rate of $87.1 \%$, and that home values are given a large weight in Method \#3. The median-weighted formula gives primary residences a high weight because both the ownership rate and median values is high for this asset. Thus, Method \#3 may give a better reflection of the degree of item response in a households' typical wealth portfolio than Method \#1.

However, while these three formulas yield different values for the level of item response in a survey, all formulas present similar answers for how item response varies across surveys. To illustrate this point, I compare item response in wealth estimates between the 2008 SIPP, 2014 SIPP, and 2013 SCF. The U.S. Census Bureau redesigned SIPP starting with the 2014 Panel, at which time numerous changes were made to the survey. The asset section underwent a major revision; new assets were added and asset income and values were asked together rather than in separate sections. Thus, comparing the 2014 SIPP wealth data to other surveys serves as a useful case study for these new item response calculations. Using the three proposed composite response rate methods, the results in general show that overall item response rates increased for wealth questions in the new panel, but are still lower than in the SCF. Given this trend is found in all the methods, the results suggest that these findings are due to real trends found in the data and not due to idiosyncratic features of any one formula. In addition, I also present results that incorporate unit response rates into the calculations. Once unit response rates are incorporated, 2014 SIPP has a higher combined response rate for wealth than the SCF.

In summary, these three proposed aggregation methods 1) provide a concise summary of item response for key estimates and 2) help compare item response rates for composite measures across surveys. While a researcher could compare item response rates for individual questions between the two surveys, this task would be difficult given the large number of questions and issues with comparability of question text and concepts. Each of the three proposed methods have strengths and weaknesses for their inferential ability. Thus, recommendations for which method to use depends on the key statistic of interest. 
For median wealth, Method \#3 may be the most useful as it offers the benefits of being less sensitive to outliers than Method \#2 and being more reflective of average item response tendencies than Method \#1. Method \#2 may be more useful for looking at total wealth, and Method \#1 may be more useful for key statistics composed from a small number of discrete-choice questions. However, the case study in this article suggests that all methods will yield similar conclusions when comparing response rates across surveys.

The remainder of the article proceeds as follows. Section 2 gives a description of the SIPP and SCF data and highlight response rates for some key variables. Section 3 discusses the new methods for aggregating data on response rates. Section 4 presents a comparison of the three methods using 2014 SIPP wealth data. Section 5 presents the results comparing 2008 SIPP, 2014 SIPP, and 2013 SCF to demonstrate how the methods may be compared across surveys. Section 6 discusses how these methods can be modified for non-continuous variables. Finally, Section 7 concludes.

\section{Background}

Before presenting the methods for aggregating item response rates, I first present an overview of the SIPP and SCF data and highlight response rates for a few variables. This discussion will show that comparing question-level response rates over time and across surveys is difficult in light of questionnaire differences, suggesting the need for an alternative measure for comparing item response rates over time.

\subsection{Description of Datasets}

The SIPP is a longitudinal survey conducted by the U.S. Census Bureau that collects information about the income, assets, labor market activity, and participation in government programs of U.S. households (U.S. Census Bureau 2016). Information on a wide variety of assets and debt is collected and includes financial variables such as the value of savings accounts, checking accounts, retirement accounts, real estate, and credit card debt. SIPP interviews households for a period of about 2.5 to 5 years (depending on the panel), with each panel containing a new set of households. Households are interviewed primarily in person, with some interviews conducted via phone. The survey attempts to interview individually every adult in the household, although some personal interviews are "proxy interviews" in which another household member provides the information about the respondent. In order to improve estimates of receipt from government programs, SIPP oversamples low-income areas.

In the 2014 panel, the U.S. Census Bureau made many changes to the survey. One substantial change is that SIPP now interviews respondents less frequently in order to reduce costs (U.S. Census Bureau 2016). In earlier panels, interviews occurred every four months, but in the 2014 panel, interviews occurred once per year. However, interviews with questions on asset values occurred about once a year in previous panels, with some gaps across time. Therefore, SIPP collects wealth data with roughly the same frequency in the 2014 Panel as before. Another change was the introduction of the event history calendar (EHC), which is a visual method of collecting retrospective data on the timing of events, such as the loss of a job or health insurance coverage. This change was made to help reduce any negative impacts of the longer recall period on data quality. 
The asset section also underwent a major revision. SIPP now collects data on additional assets that were not asked about previously, such as annuities, trusts, student loans, and education savings accounts. Moreover, questions on asset income and asset values are now asked concurrently rather than in separate sections of the interview. Wording for many questions changed as well. Because so much of the survey was modified, the quality of the net worth data may have changed substantially. These survey changes appear to have resulted in higher estimates of median wealth in 2014 SIPP compared to 2008 SIPP (Eggleston and Gideon 2017).

To evaluate the effects of the SIPP redesign on item response rates, a useful comparison survey is the SCF. The SCF is a survey sponsored by the Federal Reserve studying the income and wealth of US families (Bricker et al. 2017). Because SCF has more detailed wealth questions and its interviewers receive more training about types of assets, it has been labeled as the "gold standard" for wealth data, and thus can serve as a basis for comparison to any survey aiming to measure wealth in the United States. The National Research Council (2009) is one among many sources that have applied this label in reference to SCF. Historically, SIPP has had lower estimates of wealth than the SCF, although these discrepancies decreased in the 2014 Panel (Eggleston and Gideon 2017).

While both SIPP and SCF draw their samples from the general U.S. population and have similar content, there are several methodological differences between the surveys that might explain differences in their estimates of wealth and their item response rates. The SCF oversamples high-income individuals based on data from the Internal Revenue Service (IRS) in order to improve its estimates of income and wealth among high-wealth families. This sampling is in contrast with SIPP, which oversamples low-income areas. While weighting should theoretically result in both surveys producing similar estimates, the surveys may differ in the precision of their estimates for certain subpopulations.

In addition, SCF has a much smaller sample size than SIPP. The 2013 SCF contains about 6,000 families, while wave 1 of the 2014 SIPP Panel contains about 30,000 households, and the first wave of the 2008 Panel contains about 42,000 households. Both surveys primarily interview households in person. However, the SCF only interviews one person in the household, which is in contrast with SIPP that attempts to interview every adult in the household. Finally, the 2013 SCF offered a conditional USD 50 incentive (Hsu et al. 2017), while the 2008 and 2014 SIPP offered a USD 0, USD 20, or USD 40 incentive depending on a household's assigned experimental condition (Westra et al. 2015).

\subsection{Item Response Rates for Individual Questions}

To introduce how item response varies across the surveys and across questions, Table 1 presents item response rates for some variables in 2008 and 2014 SIPP panels and 2013 SCF. In this table, I define item response rates as the proportion of people who gave an answer (numeric value) to the respective wealth question. This classification excludes people who gave an answer of "don't know" or "refuse" to a question, or who drop out of the survey before reaching the particular asset question. This table contain standards errors for the response rates to account for sampling error. Sampling error could cause one of the surveys to have more item response among respondents, even if the questionnaire was identical. For SIPP, the individual providing information could either be the person 
Table 1. Response rates for individual wealth variables.

\begin{tabular}{l|ccc}
\hline Value variable & SIPP 2014 & SIPP 2008 & SCF 2013 \\
\hline Primary residence & $87.1(0.28)$ & $75.1(0.48)$ & $90.6(0.81)$ \\
IRA/Keogh Retirement account & $59.2(0.67)$ & & \\
IRA retirement account & & $46.2(0.64)$ & \\
Keogh retirement account & & $28.5(1.87)$ & $64.2(14.4)$ \\
Regular IRA account & & & $74.9(2.69)$ \\
Roth IRA account & $47.2(2.58)$ & & $76.8(3.3)$ \\
Trusts & & & $70.6(7.52)$ \\
\hline
\end{tabular}

Source: 2008 SIPP Panel (Wave 4), 2014 SIPP Panel (Wave 1), and 2013 SCF. Table presents item response rates for a small set of value variables. Replicate weights used to construct standard errors in all three surveys, and imputation implicates were used to construct the standard error for SCF. Standard errors shown in parenthesis.

in question or another household member providing a proxy interview. Thus, proxy responses are counted in the pool of item responders. Households that have unit nonresponse are dropped from the sample, so they are not included in the item response rate calculations for this table. In SIPP, if no one in the household responds, then the household is considered to be a unit nonresponder. In some other households, one person is interviewed but other people are unable to be interviewed (either in person or through a proxy interview). These noninterviewed people are treated as item nonresponders, so they are included in the item response rate calculations.

For some variables, such as the value of primary residences, there is a directly comparable variable in all three surveys. Table 1 shows that the item response rate for primary residences increased in SIPP from $75.1 \%$ to $87.1 \%$ after the redesign, but is still lower than the 2013 SCF rate of $90.6 \%$. These differences are surprising, given the question text for the home value question is very similar amongst all the surveys (Eggleston and Gideon 2017).

For other variables, comparisons between the 2008 and 2014 SIPP Panels and 2013 SCF are not clear cut. For example, the 2008 SIPP and 2013 SCF have separate questions on Individual Retirement Account (IRA) and Keogh retirement account balances (types of taxadvantaged investment accounts available in the United States), but the 2014 SIPP Panel has one combined question. In addition, the SCF has a separate question on Roth IRA accounts and Regular IRA accounts, but SIPP does not make this distinction. Because of these differences, it is unclear how to compare response rates for IRA accounts across these surveys. Another complication arises for when a new question is added to the survey. For example, a direct question on trusts was added to SIPP in the 2014 Panel, and this item has a low item response rate of $52.8 \%$. In some ways, data quality should be improved with the addition of this question because information on trust values is now gathered in its own question rather than through a catch-all question that asks respondents to report any other asset that haven't been asked about already. On the other hand, data quality might have decreased because this new question has a low response rate. Because new questions have no analogues from prior surveys, evaluating the effects of new variables on overall data quality needs to be addressed in a different way than variable-to-variable comparisons in response rates. 


\section{Equations for Item Nonresponse for Composite Variables}

Because of the difficulty in comparing item response rates question by question, as described above, there needs to be a way of aggregating item nonresponse data across variables in order to generate statistics which can be used to compare response rates across surveys or over time within one survey. This section presents three different ways of aggregating response rates over several variables. In this section, the focus is on continuous numeric variables, such as income and the monetary value of assets, but I discuss at the end of the article in Section 6 how the results can be generalized to other types of variables.

One feature of continuous numeric variables is that the data can exhibit varying degrees of item nonresponse. For some questions about monetary amounts, respondents who give an initial answer of "don't know" or "refuse" are asked a range follow-up question (e.g., "is the value less than USD 500, between USD 500 and USD 1,000, or more than USD 1,000 "). To denote a person's type of item response, let individual $i$ 's response to question $q$ be indicated by $r_{i, q}$, where $r_{i, q}=1$ if the individual responds to the numeric question, $r_{i, q}=1 / 2$ if the individual does not answer the numeric question but gives an answer to a range follow-up question, $r_{i, q}=0$ if the individual does not respond to either the numeric question or the range follow-up question, and $r_{i, q}=N I U$ if the person is not in universe (i.e., not on path) for the question.

In addition, weights are important to include in the response rate formulas because of potential survey design effects. For example, SIPP oversamples low-income areas and SCF oversamples high-income households. If item response propensities vary by income or income is correlated with other factors that affect response propensities (such as household size), then ignoring weights would cause item response comparisons between the surveys to be conflated with these sampling factors. Because of this factor, I use the variable $w_{i}$ to denote the survey (adjusted) weight for individual $i$. Using adjusted weights accounts for over-sampling and nonresponse of certain populations, allowing the item response rates to reflect the odds that a random person from the population would respond to the question. However, if a researcher is only interested in calculating the prevalence of item nonresponse in a single survey (without any cross-survey comparisons), then excluding weights may be beneficial, as this would give the percent of the sample with item nonresponse.

\subsection{Percent with no Missing Value}

The first aggregation method calculates the proportion of individuals who give a response to every question used to create the composite variable $c$, given by the expression

$$
1-\frac{\sum_{i=1}^{n} w_{i} \max \left(d_{c, 1} 1\left(r_{i, 1} \in\{0,1 / 2\}\right), \ldots, d_{c, Q} 1\left(r_{i, Q} \in\{0,1 / 2\}\right)\right)}{\sum_{i=1}^{n} w_{i} \max \left(d_{c, 1} 1\left(r_{i, 1} \neq N I U\right), \ldots, d_{c, Q} 1\left(r_{i, Q} \neq N I U\right)\right)}, \# M 1(c)
$$

where $d_{c, q}=1$ if the survey or researcher uses question number $q$ to construct composite variable number $c$, and zero otherwise. One advantage of Method \#1 is that it is straightforward to explain and understand. Method \#1, unlike Methods \#2 and \#3 below, does not require imputed values for when the variable is missing. In addition, as some 
researchers drop imputed values from their analyses, this statistic gives an indicator of the proportion of the sample that would be kept if imputed values are excluded. The formula for Method \#1 does not incorporate any range follow-up information into the response rate calculation, which is done for simplicity in this article. However, the express $r_{i, 1} \in$ $\{0,1 / 2\}$ in the numerator in the formula for Method \#1 could be modified to $r_{i, 1} \in\{0\}$ to give the rate of people who gave at least a range follow-up response to every question.

The main disadvantage of Method \#1 is that it does not capture varying degrees of item response across questions that may be meaningful. For example, Method \#1 does not describe whether households tended to give an answer of "don't know" or "refuse" only for a small number of questions or for most questions in the survey. Also, the more questions that are used to create the composite variable, the more likely it is that the household will not give an answer to at least one question, which may create a false sense of inaccuracy for composite variables that are created for a large set of detailed questions.

\section{2. $\quad$ Sum-Weighted Response Rates}

The second aggregation method is calculated by taking the weighted sum of values (using survey weight $w_{i}$ ) with a given response type $k$ (e.g., gave a range follow-up response) divided by the weighted sum of all values. The formula for Method \#2 is given by the expression

$$
\sum_{i=1}^{n} w_{i}\left(\sum_{\mathrm{q}=1}^{\mathrm{Q}} d_{c, q} 1\left(r_{i, q}=k\right) x_{i, q}\right) / \sum_{i=1}^{n} w_{i}\left(\sum_{\mathrm{q}=1}^{\mathrm{Q}} d_{c, q} x_{i, q}\right), \# M 2(c, k)
$$

in which $x_{i, q}$ is the actual response or the imputed value for individual $i$ for question number $q$. Because imputed data are used for item nonresponders, this method can only be used in surveys that impute data for people with missing data.

For $k=1$, as an example, Method \#2 represents the percent of all values for composite variable $c$ that consist of reported values. Because this method is separated by response type, there are three rates generated by this method (Reported, Complete Nonresponse, and Range Follow-up Response). Hokayem et al. (2017) use such a formula to describe response rates for household income in the CPS Annual Social and Economic Supplement. One advantage of Method \#2 over Method \#1 is that it gives more weight to assets that have larger values, on average. For example, if home equity constitutes a larger proportion of household net worth than bank accounts, then the sum-weighted formula (Method \#2) would put more weight on imputed home values than bank account values. Method \#1 gives equal weight to home value and bank account values if the household owns both assets, which may be undesirable if a researcher is concerned about assets that constitute a larger proportion of wealth portfolios.

One potential disadvantage of the sum-weighted formula (Method \#2) is that respondents with larger values are given more weight than other respondents. To consider a trivial example, suppose a dataset consists of two observation with values of USD 1 and USD 1 million, and only one of the values is imputed. The calculated response rate (the rates of reporting a value) for Method \#2 would be nearly $100 \%(1,000,000 / 1,000,001)$ if the USD 1 observation was the imputed value, but the response rate would be nearly $0 \%$ 
$(1 / 1,000,001)$ if the USD 1 million observation was imputed (whereas, for Method \#1, both cases would result in a calculated response rate of 50\%).

This effect also comes into play for wealth data. If high-wealth households have lower response rates than other respondents, then this facet of the data will cause the rate for Method \#2 to be higher. Lillard et al. (1986), for example, find that high-income respondents are less likely to answer the wage question in the CPS. The influential effect from respondents with large values may be desirable when looking at statistics based on a mean or sum, such as aggregate income or net worth, as such statistics are influenced heavily by outliers. However, if a researcher is focused on median net worth instead, then this item response statistic may not properly reflect the behavior of respondents in the middle of the distribution.

\subsection{Median-Weighted Response Rates}

The final formula is computed by taking a weighted average of response rates from each question. This "importance" weight is the percent of individuals who have a non-missing and non-zero value for question $q$, denoted by $o_{q}$, times the median of non-missing and nonzero responses, denoted by $\operatorname{med}\left(x_{q}\right)$. Both $o_{q}$ and $\operatorname{med}\left(x_{q}\right)$ can be constructed with survey weights. For assets, $o_{q}$ represents the ownership rate for a given asset while for income, $o_{q}$ represents the proportion of people who are receiving a particular source of income.

With this notation, the median-weighted item response rate for composite variable $c$ is denoted by

$$
\left(\sum_{\mathrm{q}=1}^{\mathrm{Q}} d_{c, q} o_{q} \operatorname{med}\left(x_{q}\right) p_{q, k}\right) /\left(\sum_{\mathrm{q}=1}^{\mathrm{Q}} d_{c, q} o_{q} \operatorname{med}\left(x_{q}\right)\right), \# M 3(c, k)
$$

in which $p_{q, k}$ is the item response rate for question $q$ (constructed with survey weights), and the product $o_{q} \operatorname{med}\left(x_{q}\right)$ is the importance weight given to each question. In Method \#3, more weight is given to variables with a higher ownership (non-missing and non-zero) rate, and higher median values. Similar to Method \#2, Method \#3 gives more weight to more "important" variables that constitute a larger proportion of the composite variable. As with Method \#2, Method \#3 generates three rates for the three different types of response outcomes, and can only be used for surveys that impute data for missing values. However, one benefit of Method \#3 over Method \#2 is that the statistic is less influenced by outliers, which could be useful in order to gauge the nonresponse behavior of the "typical" respondent, or for analyzing the impact of item nonresponse on median estimates.

To help provide context for the median-weighted formula, Table 2 presents ownership rates and median values in 2014 SIPP for select variables, as well as the importance weight for these variables (before they are normalized to sum to one). This table shows that primary residences are given a large importance weight because $58.9 \%$ of households own a home, and the median home value is USD 180,000, which generates an importance weight of $o_{q} * \operatorname{med}\left(x_{i, q}\right)=188,000 * 58.9=10,602,000$ (these statistics exclude mobile homes, which are captured through a separate variable). The importance weight for $401 \mathrm{k}$ and thrift accounts is $17.2 \%$ of the weight for primary residence, as the ownership rates are 
Table 2. Ownership rates and median values for individual wealth variables (2014 SIPP).

\begin{tabular}{|c|c|c|c|c|}
\hline Variable & $\begin{array}{l}\text { Ownership } \\
\text { rate }\end{array}$ & $\begin{array}{l}\text { Median } \\
\text { value }\end{array}$ & $\begin{array}{l}\text { Weight } \\
\text { (in thousands) }\end{array}$ & $\begin{array}{l}\text { Weight as a } \\
\text { percentage of } \\
\text { the primary } \\
\text { residence } \\
\text { weight }\end{array}$ \\
\hline Primary residence & 58.9 & 180,000 & 10,602 & 100.0 \\
\hline $\begin{array}{l}401 \mathrm{k} / \text { Thrift retirement } \\
\text { account }\end{array}$ & 40.2 & 45,300 & 1,821 & 17.2 \\
\hline $\begin{array}{l}\text { IRA/Keogh retirement } \\
\text { account }\end{array}$ & 28.1 & 40,000 & 1,124 & 10.6 \\
\hline $\begin{array}{l}\text { Savings account } \\
\text { (own name) }\end{array}$ & 48.4 & 1,400 & 68 & 0.6 \\
\hline $\begin{array}{l}\text { Interest checking } \\
\text { (own name) }\end{array}$ & 22.5 & 2,000 & 45 & 0.4 \\
\hline $\begin{array}{l}\text { Education savings account } \\
\text { (first account) }\end{array}$ & 4.0 & 10,000 & 40 & 0.4 \\
\hline Trusts & 1.5 & 100,000 & 150 & 1.4 \\
\hline
\end{tabular}

Table presents ownership rates and median values for select variables from SIPP. In addition, to help explain the median-weighted formula for allocation, this table also shows the weight of the ownership rates times the median value, and the percentage the weight is of the weight for primary residences. Because SIPP is a household survey, I construct the ownership rates and the median values at the household level, even for questions asked to every adult in the household.

Source: 2014 SIPP Panel (Wave 1).

lower and the median value is about USD 45,000. IRAs follow a similar pattern with an importance weight that is $10.6 \%$ of the importance weight for primary residence. Other assets presented in this table have a much lower importance weight. Because savings accounts held in someone's own name have a median value of only USD 1,400, the importance weight is $0.6 \%$ of the weight for primary residences. Even though trusts have a median value of USD 100,000, the importance weight for trust is $1.4 \%$ of the importance weight for primary residences since the ownership rate is $1.5 \%$. In summary, this table shows that when applying the median-weighted formula for all assets and debt in 2014 SIPP, the item response rates for home values and retirement account balances are given a relatively high importance weight, while bank accounts and trusts have a much lower importance weight.

To show how the methods presented in Section 3 can be used to summarize item response rates concisely for key aggregate measures in a survey, the next two sections apply these methods to wealth data. Section 4 provides a comparison of the three methods using 2014 SIPP for a variety of wealth categories. Section 5 presents the results comparing 2008 SIPP, 2014 SIPP, and 2013 SCF to demonstrate how the methods may be compared across surveys.

\section{Comparison of Composite Response Rate Methods}

Table 3 presents composite response rates for wealth questions in the 2014 SIPP. This table organizes assets into broad categories, such as bank accounts. Figure 1 also presents the same numbers graphically for the response rates for the three methods. 


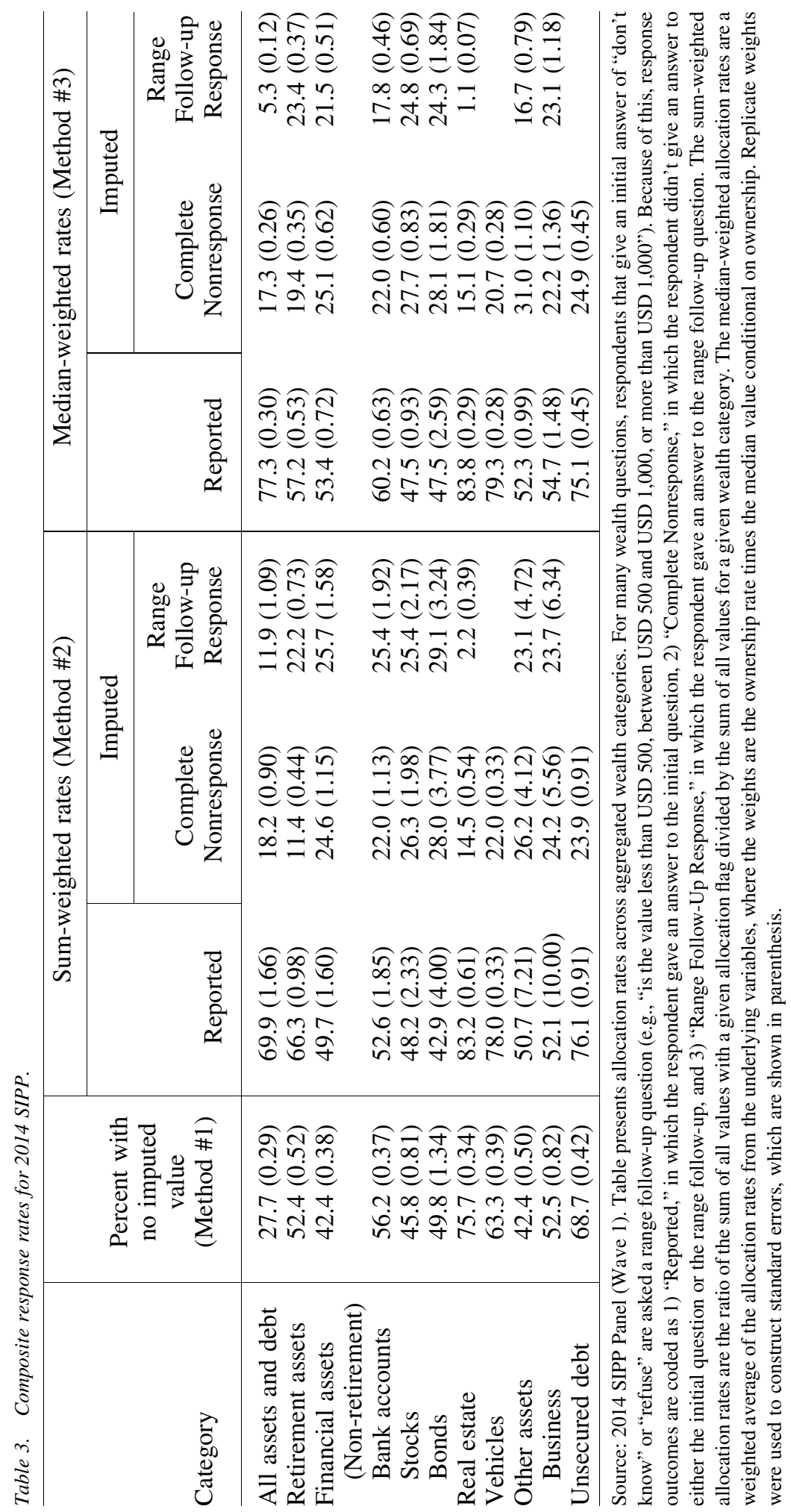




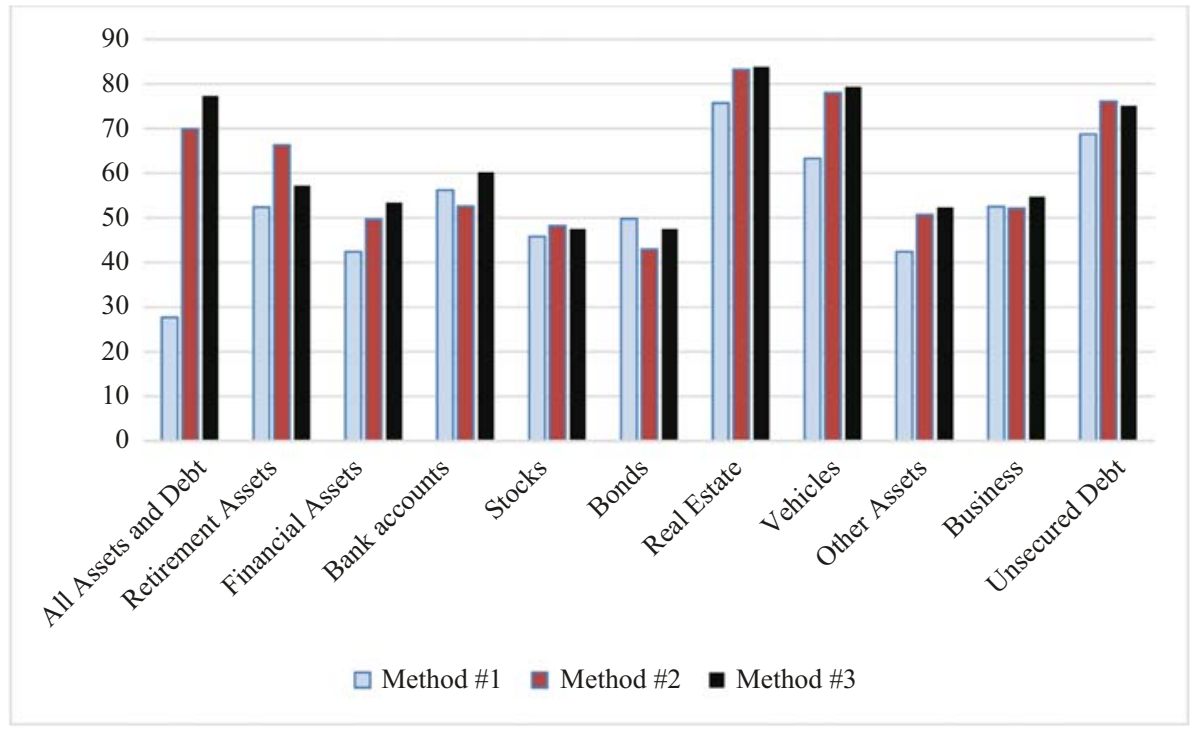

Fig. 1. Response rates from Table 3.

Source: 2014 SIPP Panel (Wave 1). Figure presents the response rates from Table 3 for the three item response rate formulas for composite variables. For Method \#2 and \#3, the estimate displayed in this figure is the "reported" rate shown in Table 3.

Details about these categories are presented in Appendix (Section 8). Because SIPP is a household survey and some of the composite variables are at the household level, I let the indicator of having no imputed values equal zero if anyone in the household has an imputed value. In addition, for the median-weighted response rate, I construct the ownership rates and the median values at the household level, even for questions asked to every adult in the household. In SIPP, some questions, such as home values, are asked to only one member in the household, while other questions are asked to every individual over 15 .

The first column of numbers in Table 3 presents the rates for having no imputed values (Method \#1). When looking at any asset or debt variable, $27.7 \%$ of households in the 2014 panel have no imputed value. Rates vary across assets, with the rates being high for real estate $(75.7 \%)$, but lower for stocks $(45.8 \%)$.

The second set of columns presents the sum-weighted response rates (Method \#2). Note that for many wealth questions, respondents who give an initial answer of "don't know" or "refuse" are asked a range follow-up question (e.g., "is the value less than USD 500, between USD 500 and USD 1,000, or more than USD 1,000"). Because of this distinction, response outcomes are coded as 1) "Reported", in which the respondent gave an answer to the initial question, 2) "Complete Nonresponse", in which the respondent didn't give an answer to either the initial question or the range follow-up, and 3) "Range Follow-Up Response", in which the respondent gave an answer to the range follow-up question. For example, the sum-weighed numbers for bank accounts indicate that respondents gave a response to the question $52.6 \%$ of the time. For the other outcomes, respondents gave a response to the range follow-ups for bank account $25.4 \%$ of the time, and had complete nonresponse $18.2 \%$ of the time. 
For the sum-weighted response rates (Method \#2), the relative pattern between assets in response rates is similar to the no-imputed-value method. For example, the sumweighted response rates for real estate is higher than the response rate for stocks, which is the same pattern that is found for Method \#1. For stocks, even though about half of the data is imputed, about a quarter of the data consists of imputed data from range follow-up responses, so a sizable proportion of respondents are still providing some information about their stock values. While the relative patterns between assets is similar, the overall response rate for all wealth items is very different. Method \#2 yields a response rate of $69.9 \%$, even though only $27.7 \%$ (Method \#1) of households have no imputed asset or debt item. These estimates suggest that while the majority of households have at least one imputed wealth item, the majority of household wealth consists of reported values.

One inherent characteristic of the sum-weighted formula (Method \#2) is that more weight is given to observations with larger values. To elaborate on this point, Table 4 shows how the overall sum-weighted reporting rate (Method \#2) for asset and debt items varies by net worth quintile. This table shows that for observations in the bottom fifth of the wealth distribution, the overall weighted response rate is $83 \%$, but the response rate drops to $67.5 \%$ for the top fifth of the wealth distribution. This result could be driven either by high-wealth individual being less likely to respond for any given question, or because high wealth households hold assets like trusts, which have lower item response rates. To describe the relative weight each quintile has on the sum-weighted response rate (Method \#2), Table 4 also shows the percent of aggregate assets that are held by each quintile of the wealth distribution. Aggregate assets are shown because, unlike net worth, assets are greater than or equal to zero for every household, which prevents the percent aggregate statistics from being negative for any quintile. These results show that the top quintile of the wealth distribution holds $89.5 \%$ of total assets, suggesting that the item response behavior of the top quintile is given a large weight when looking at item response rates for the entire sample.

In contrast with the sum-weighted formula (Method \#2), the median weighted formula (Method \#3) is much less sensitive to outliers given the inherent nature of medians. Table 3 shows the median-weighted response rates (Method \#3) in the last set of columns. For all assets and debt variables, the response rate is $77.3 \%$ with Method \#3, compared to $69.9 \%$ for the sum-weighted formula (Method \#2). The response rate for

Table 4. Response rates and percent of aggregate assets by net worth quintile (Method \#2).

\begin{tabular}{l|ll}
\hline Net worth quintile & Percent wealth reported, sum weighted Percent aggregate assets \\
\hline
\end{tabular}

\begin{tabular}{l|rr}
\hline $1^{\text {st }}$ (Lowest) & $83.0(0.91)$ & $2.1(0.14)$ \\
$3^{\text {rd }}$ (Middle) & $77.1(0.63)$ & $8.4(0.41)$ \\
$5^{\text {th }}$ (Highest) & $67.5(2.40)$ & $89.5(0.53)$ \\
\hline
\end{tabular}

Table presents allocation rates across all wealth variables by net worth quintile, and the percent of aggregate assets held by each net worth quintile. The allocation rates are the ratio of the sum of all values with a given allocation flag divided by the sum of all values for a given wealth category. Replicate weights were used to construct standard errors, which are shown in parenthesis.

Source: 2014 SIPP Panel (Wave 1). 
some other asset groups are higher as well with the median-weighted formula, such as the rate for bank accounts (60.2\% versus 52.6\%). However, the response rate for retirement assets is actually lower with the median-weighted formula (Method \#3) at $57.2 \%$, compared to the rate of $66.3 \%$ for the sum-weighted method (Method \#2). One explanation for this result could be that people who are retired or close to retirement may be more aware of their retirement account balances than younger workers who are decades away from retirement. If awareness is related to item response rates and if older individuals have higher account balance, these factors could result in people with higher retirement account balances having higher item response rates for this asset. These differences in item response rates between groups would then cause the sum-weighted (Method \#2) formula to have higher response rates for retirement accounts, as the people with higher values are the ones with higher response rates in this case. These examples illustrate that there is no fixed relationship between the response rate method and the value of the calculated rate. Each method may produce a higher or lower rate than another depending on the specific characteristics of the composite measure and respondent behavior.

All together, the results from Table 3 suggest that the majority of wealth data consists of reported rather than imputed data, even though the majority of households are missing data for at least one asset or debt question. To help provide more intuition for this point, Table 5 presents the relative weight each of the asset and debt categories have when calculating the median-weight response rate (Method \#3) for all asset and debt items. As suggested by earlier results, Table 5 shows that the response rate for real estate (which includes home values) make up $70.3 \%$ of the overall response rate, and retirement accounts make up $12.0 \%$. Bonds, which are a more uncommon asset, only make up $0.3 \%$ of the overall response rates. The weight real estate is given in Method \#3 is reflective of how home equity constitutes a large proportion of many people's net worth. For example, in 2014 SIPP (Wave 1) median net worth is USD 80,039, but when home equity is excluded, the median drops by $68.6 \%$ to USD 25,116 (U.S. Census Bureau 2017). While there are some

Table 5. Decomposition of median-weighted formula (Method \#3).

\begin{tabular}{l|c}
\hline Category & Percentage total weight \\
\hline Retirement assets & $12.0(0.33)$ \\
All financial assets not in retirement accounts & $5.5(0.16)$ \\
Bank accounts & $2.5(0.09)$ \\
Stocks & $2.7(0.13)$ \\
Bonds & $0.3(0.06)$ \\
Real estate & $70.3(0.46)$ \\
Vehicles & $6.0(0.07)$ \\
Other assets & $4.0(0.35)$ \\
Business & $1.3(0.30)$ \\
Unsecured debt & $2.2(0.07)$ \\
\hline
\end{tabular}

Table presents the percentage contribution each group's item response rate has when constructing the medianweighted response rate (Method \#3). Replicate weights were used to construct standard errors, which are shown in parenthesis.

Source: 2014 SIPP Panel (Wave 1). 
assets like trusts that have a response rate of under 50\%, many of the assets which constitute a larger proportion of many people's net worth, such as home values, have a much higher response rate. Overall, Table 5 shows that for these particular measures the assets with lower response rates also happen to contribute less to net worth and thus are given less weight in the median-weighted response rate formula (Method \#3). Though this pattern may not always be the case, it is likely that an item's importance and its item response rate would often be positively correlated due to increased salience to respondents or increased effort on the part of the survey sponsor to measure it well.

\section{Comparison Across Surveys}

The previous section focused on how the proposed item response formulas can be used to summarize item response for a key measure in one survey concisely. However, another use of these formulas is to compare item response rates across surveys. Table 6 presents results comparing response rates between 2008 SIPP, 2014 SIPP, and 2013 SCF using the three different methods. For expositional purposes, Table 6 only presents the results for all combined asset and debt categories.

Overall, this table shows that response rates went up in SIPP after the 2014 redesign, but the rates are still lower than SCF rates. For the median-weighted response rate (Method \#3), 2008 SIPP has a rate of 68.8\%, 2014 SIPP has a rate of 77.3, and SCF has a rate of $85.0 \%$. Of all respondents with some degree of item nonresponse, SCF also has more individuals whose values are imputed from a range (as opposed to being imputed without any respondent reported value information) than SIPP. In 2014 SIPP, $23.3 \%$ of respondents who didn't respond initially have a value that is imputed from a range (as computed from the estimates displayed in Table 6), but this rate is $78 \%$ for SCF respondents. In this statistic on range follow-ups, the 23.3 estimate for SIPP is not shown in Table 6 but rather is computed as the imputed within range estimate (5.3) divided by the total imputation rate (100-77.3). The SCF estimate is constructed analogously. In addition, SCF allows respondents to give their own bounds for a range follow-up response, which may result in SCF having more people in this response category.

A similar relative pattern between surveys is found for the sum-weighted response rate (Method \#2). For the rates of having no imputed values (Method \#1), the relative pattern is slightly different. 2014 SIPP has the lowest rate at $27.7 \%$, while 2008 SIPP is in the middle at $29.7 \%$. This difference could be the result of 2014 SIPP having a greater number of asset and debt questions, which would give respondents more opportunity to item nonrespond to at least one question. But overall, the relative differences in response rates are fairly consistent across the three methods, suggesting that the results are not based on idiosyncratic features of any one formula.

Though the nature of the differences in rates across surveys is fairly clear, the reasons for these differences is more uncertain. For example, item response rates for primary residences are different amongst all three surveys (see Table 1), even though the question text for primary residences is similar between the surveys (Eggleston and Gideon 2017). Hard-to-quantify characteristics, like context effects or variation in interviewer training, could also explain the differences between the three surveys. 


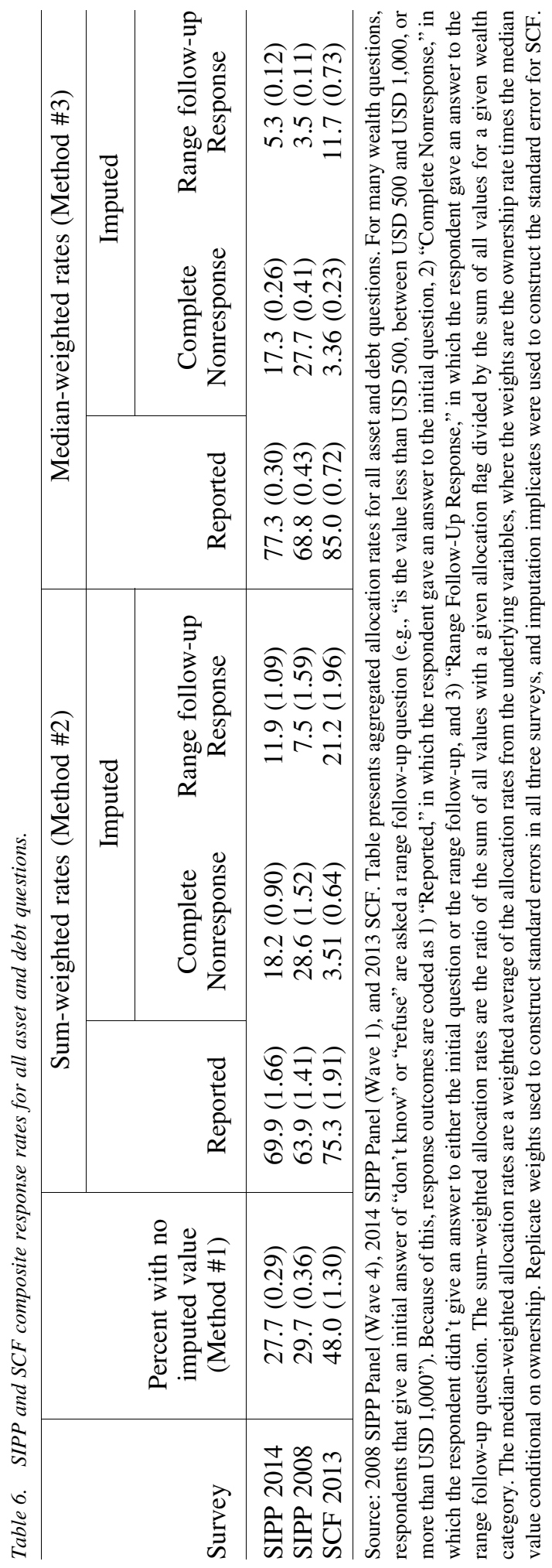


Table 7. Median-weighted response rates (Method \#3).

\begin{tabular}{l|c|cc}
\hline Category & $\begin{array}{c}\text { Unit } \\
\text { response } \\
\text { rate }\end{array}$ & $\begin{array}{c}\text { Median-weighted } \\
\text { item response rate } \\
\text { (Method \#3) }\end{array}$ & $\begin{array}{c}\text { Combined response } \\
\text { rate (Product of previous } \\
\text { two columns) }\end{array}$ \\
\hline SIPP 2014 & 68.8 & $77.3(0.30)$ & $53.2(0.21)$ \\
SIPP 2008 & 67.6 & $68.8(0.43)$ & $46.5(0.29)$ \\
SCF 2013 & 56.5 & $85.0(0.72)$ & $48.0(0.41)$ \\
\hline
\end{tabular}

Source: 2008 SIPP Panel (Wave 4), 2014 SIPP Panel (Wave 1), and 2013 SCF. Table presents survey response rates and allocation rates across aggregated wealth categories. Last column is the multiplication of the two previous columns. The median-weighted allocation rates are a weighted average of the allocation rates from the underlying variables, where the weights are the ownership rate times the median value conditional on ownership. Replicate weights were used to construct standard errors, which are shown in parenthesis.

Another potential reason for the differences in item response rates is differences in unit response rates. SIPP unit response rates (AAPOR RR6) are $80.6 \%$ in the 2008 Panel (Wave 1) but only $68.8 \%$ in the 2014 Panel. This decline is consistent with the downward trend in unit responses rates for federal surveys in the United States. For example, the unit response rates in the National Health Interview Survey decreased from $84.9 \%$ in 2008 to $73.8 \%$ in 2014 (Czajka and Beyler 2016). The 2013 SCF has a response rate (AAPOR RR1) of about $65 \%$ for the general population sample, but a rate of about one-third for the high wealth oversample (Bricker et al. 2017). Yan et al. (2010) find that decreasing unit response rates in the Survey of Consumers has been associated with higher income item response rates, potentially suggesting that people who are not interviewed for the survey would also be more likely to have item nonresponse if they responded. This finding would suggest that part of the reason for differences in item response rates is differences in unit response rates.

To account for the effect of unit response when comparing response rates for composite variables across surveys, Table 7 presents the median-weighted response rates (Method \#3) multiplied by the unit response rate for the survey. The estimates for 2008 SIPP use the cumulative unit response rate, which is the initial unit response rate at Wave 1 times the total attrition rate as of Wave 4, which is the first wave in which wealth data are collected. The unit response rate for SCF is somewhat difficult to construct since the Federal Reserve doesn't publish one combined unit response rate for the SCF. To construct one, I weight the response rate for the general population sample and the highwealth sample by their sample sizes, which is listed online in the SCF codebook (Board of Governors of the federal Reserve System 2017) to construct a combined rate of $56.5 \%$. To construct a combined response rate, the ideal method would be to weight by the inverse of the probability of selection rather than sample size. However, given the former information is not available on the publicly available dataset, using the sample size is the next best method.

In this combined rate, the relative standing of SCF changes compared to what is observed in Table 6. The 2008 SIPP still has the lowest rate of $46.5 \%$, but the 2013 SCF is now lower than 2014 SIPP (48.0\% versus 53.2\%). Thus, when comparing response rates for composite variables across surveys, differences in unit response rates are important to take into consideration as well. If unit response is low, item response may be high, but both factor likely influence data quality and potential for nonresponse bias. 


\section{Non-Continuous Variables}

Most of the article has focused on continuous variables such a household income or wealth. However, some measures, such as the unemployment rate, are based on a series of yes/no and discrete-choice questions, rather than on continuous variables. For such variables, aggregated measures of item response can also be constructed by modifying some of the formulas already presented in Section 3. The statistic of having no imputed values (Method \#1) is easy to extend to non-continuous variables, as this method does not rely on the underlying variables being continuous. In addition, the equation for the median-weighted response rate (Method \#3) can be modified to remove the median function from the weight to generate a statistic for non-continuous variables. In this revised formula for Method \#3, more weight is given to questions that are on-path/ in-universe for a larger set of respondents, which similarly gives more weight to more "important" questions. Since Method \#2 relies on continuous amounts, this method cannot be modified for discrete-choice questions.

As a simple example, consider a composite response rate for whether someone is disabled. In SIPP, this indicator equals one if any of the six underlying core disability questions (Hearing, Seeing, Cognitive, Ambulatory, Self-Care, Independent Living) has a response of "yes". For the no-imputed-value formula (Method \#1), this rate would be the percent of people who item respond to all of the disability question. For the modified Method \#3, this rate would be the average of the response rates to the six disability questions, since the universe of these variables is the same. These two methods may yield slightly different numbers if individuals who item nonrespond to some of the disabilities questions but not others. For example, a proxy respondent who answers questions about another household member may know whether the person has difficulty hearing but be unsure whether the person has any cognitive problems, such as difficulty concentrating. In this case, the no-imputed-value formula (Method \#1) would generate slightly lower response rates than the modified third method. As a simplified mathematical example, suppose $10 \%$ of the sample item nonresponds to all the disability questions, and a different $10 \%$ of the sample item nonresponds to just the cognitive question. In this case, the no imputed value measure would be $80 \%$, but the modified Method \#3 would be $(80+5 * 90) / 6=88.33 \%$. In summary, this method of aggregating response rates across questions is applicable to a variety of key measures, including measures based on non-continuous variables.

\section{Conclusion}

This article presents new methods for aggregating data on item response rates across questions in order to generate statistics of item response for composite measures, such as household income and wealth. These methods 1) provide a concise summary of item response for key estimates and 2) help compare item response rates across surveys, similar to American Association for Public Opinion Research (2016) unit response rates. Each of the three proposed methods have strengths and weaknesses for their inferential ability. Thus, recommendations for which method to use depends on the key statistic of interest. For median wealth, Method \#3 may be the most useful, while Method \#1 may be sufficient for composite variables composed from a smaller set of items. Table 8 summarizes the 
Table 8. Strengths and limitations of each method.

\begin{tabular}{|c|c|c|c|}
\hline & $\begin{array}{l}\text { Percent with } \\
\text { no imputed } \\
\text { value (Method \#1) }\end{array}$ & $\begin{array}{l}\text { Sum-weighted } \\
\text { rates (Method \#2) }\end{array}$ & $\begin{array}{l}\text { Median-weighted } \\
\text { response rates } \\
(\text { Method \#3) }\end{array}$ \\
\hline Strengths & $\begin{array}{l}\text { A) Simple to } \\
\text { understand } \\
\text { B) Useful when } \\
\text { only small number } \\
\text { of questions } \\
\text { are involved }\end{array}$ & $\begin{array}{l}\text { A) Captures variation } \\
\text { in item response } \\
\text { rates across questions } \\
\text { B) Useful when key } \\
\text { statistic is a mean } \\
\text { or total }\end{array}$ & $\begin{array}{l}\text { A) Captures variation } \\
\text { in item response } \\
\text { rates across } \\
\text { questions } \\
\text { B) Less sensitive to } \\
\text { outliers than } \\
\text { Method \#2 } \\
\text { C) Useful when key } \\
\text { statistics is } \\
\text { a median }\end{array}$ \\
\hline Limitations & $\begin{array}{l}\text { A) Doesn't capture } \\
\text { variation in item } \\
\text { response rates } \\
\text { across questions } \\
\text { B) Not as useful when } \\
\text { a large number of } \\
\text { questions are } \\
\text { involved }\end{array}$ & $\begin{array}{l}\text { A) Sensitive to outliers } \\
\text { B) Requires imputed } \\
\text { values for missing } \\
\text { data } \\
\text { C) More complicated } \\
\text { than Method \#1 }\end{array}$ & $\begin{array}{l}\text { A) Requires imputed } \\
\text { values for missing } \\
\text { data } \\
\text { B) More complicated } \\
\text { than Method \#1 }\end{array}$ \\
\hline
\end{tabular}

advantages and disadvantages of each method. After applying these methods to wealth data, I find item response rates went up in SIPP after the 2014 redesign, but the rates are still lower than in the SCF. However, the 2014 SIPP has higher response rates than the 2013 SCF once unit response rates are incorporated.

This comparison in item response rates amongst surveys is greatly facilitated by my methods for aggregating item response rates. The SCF, for example, has over 140 assets and liabilities questions, so analyzing item nonresponse rates for each of these questions would be tedious and burdensome for researchers and data users. In addition, many of these questions do not have a direct correspondence in SIPP, so direct comparison by question is infeasible. These aggregation methods potentially alleviate these difficulties by combining all asset and debt questions into categories that are comparable across surveys. These methods can be applied to other composite measures, such as the unemployment rate, allowing for a new way of evaluating data quality in key measures.

\section{Appendix}

In this Appendix, I describe the asset and debt groupings presented in the tables.

1. Bank Accounts: Consists of money in checking, savings, money market accounts, and Certificates of Deposit (CDs).

2. Bonds: Consists of U.S. Treasury securities, municipal bonds, and corporate bonds held outside of retirement accounts, as well as U.S. savings bonds. For SCF, this category also includes foreign and mortgage-backed bonds. 
3. Stocks: Consists of shares of stocks and mutual funds held outside of retirement accounts.

4. Financial Assets: Consists of all assets in the bank account, bonds, and stock categories.

5. Business: Consists of the value and debt of businesses. SIPP asks respondents the percent of the business that they own. I use this variable to construct the business value for the household, but I do not incorporate the item nonresponse status of the percent owned variable when calculating the response rate for businesses.

6. Other Assets: For both 2014 SIPP Panel and SCF, this consists of the cash value of life insurance policies, annuities, trusts, and the value of all other assets captured in a catchall question. For 2008 SIPP, the measure consists of only values from a catchall question, as the annuity and trust questions were added in the 2014 Panel. The 2008 measures also excludes the cash value of life insurance policies, as this variable was excluded from net worth calculations because many respondents conflated cash value and face value of life insurance (Gottschalck and Moore 2007). The 2013 SCF measure also includes money owed to the respondent by friends, family, or businesses.

7. Retirement Assets: Consists on money in Individual Retirement Accounts (IRAs), Keogh accounts, and 401k/thrift accounts.

8. Real Estate: Consists of the value of primary residences; rental property; and other real estate, such as timeshares and vacation properties. The SCF has a question about the percent of the other real estate the respondent owns. I use this variable to construct the real estate value for the household, but I do not incorporate the item nonresponse status of the percent owned variable when calculating the response rates for real estate.

9. Vehicles: Consists of cars, trucks, SUVs, and recreational vehicles such as motorcycles, boats, and RVs.

10. Unsecured Debt: For 2014 SIPP, this consists of credit cards, student loans, and other debt. For 2008 SIPP, there was no separate question on student loans, but student loans should be included with "other debt." The SCF measure includes everything collected in the 2014 SIPP as well as data on other consumer loans and lines of credit.

\section{References}

American Association for Public Opinion Research. 2016. "Standard Definitions: Final Dispositions of Case Codes and Outcome Rates for Surveys. 9th edition." AAPOR. Available at: https://www.aapor.org/Standards-Ethics/Standard-Definitions-(1).aspx. (accessed April 2019).

Bee, A. and J. Mitchell. 2017. "Do Older Americans Have More Income Than We Think?" SESHD Working Paper 2017, No. 39. Available at: https://www.census.gov/content/ dam/Census/library/working-papers/2017/demo/SEHSD-WP2017-39.pdf. (accessed April 2019). 
Board of Governors of the Federal Reserve System. 2017. Codebook for 2016 Survey of Consumer Finances. Available at: https://www.federalreserve.gov/econres/files/ codebk2016.txt. (accessed April 2019).

Bollinger, C.R., B.T. Hirsch, C.M. Hokayem, and J.P. Ziliak. 2015. "Trouble in the Tails? What We Know about Earnings Nonresponse Thirty Years after Lillard, Smith, and Welch." University of Kentucky Center for Poverty Research Discussion Paper Series, no. 120. Available at: https://uknowledge.uky.edu/ukcpr_papers/120/. (accessed April 2019).

Bound, J. and A.B. Krueger. 1991. "The Extent of Measurement Error in Longitudinal Earnings Data: Do Two Wrongs Make a Right?" Journal of Labor Economics 9: 1-24. Doi: http://dx.doi.org/10.1086/298256.

Bricker, J., L.J. Dettling, A. Henriques, J.W. Hsu, L. Jacobs, K.B. Moore, S. Pack, J. Sabelhaus, J. Thompson, and R.A. Windle. 2017. "Changes in U.S. Family Finances from 2013 to 2016: Evidence from the Survey of Consumer Finances." Federal Reserve Bulletin 100(4). Available at: https://www.federalreserve.gov/publications/ 2017-September-changes-in-us-family-finances-from-2013-to-2016.htm. (accessed April 2019).

Czajka, J.L. and A. Beyler. 2016. Background Paper Declining Response Rates in Federal Surveys: Trends and Implications. Washington: Mathematica Policy Research. Available at: https://aspe.hhs.gov/system/files/pdf/255531/Decliningresponserates.pdf. (accessed April 2019).

Eggleston, J. and M. Gideon. 2017. "Evaluating Wealth Data Quality in the Redesigned 2014 Panel of the Survey of Income and Program Participation." SIPP Working Paper, no. 278. Available at: https://www.census.gov/library/working-papers/2017/demo/ SEHSD-WP2017-35.html. (accessed April 2019).

Ferber, R. 1966. "Item Nonresponse in a Consumer Survey." Public Opinion Quarterly 30(3): 399-415. Doi: https://doi.org/10.1086/267432.

Gottschalck, A.O. and J.C. Moore. 2007. "Evaluation of Questionnaire Design Changes on Life Insurance Policy Data.” U.S. Census Research Report Series, Survey Methodology 2007(14). Available at: https://census.gov/library/working-papers/2007/adrm/rsm200714.html. (accessed April 2019).

Groves, R.M. and E. Peytcheva. 2008. "The Impact of Nonresponse Rates on Nonresponse Bias a Meta-Analysis." Public Opinion Quarterly 72(2): 167-189. Doi: https://doi.org/10.1093/poq/nfn011.

Hokayem, C., T. Raghunathan, and J. Rothbaum. 2017. "Ignorable Nonresponse? Improved Imputation and Administrative Data in the CPS ASEC." Paper presented at the Association for Public Policy Analysis and Management Fall Research Conference, November 2-4, 2017. Available at: https://appam.confex.com/appam/2017/webprogram/ Paper23281.html. (accessed April 2019).

Hsu, J.W. M.D. Schmeiser, C. Haggerty, and S. Nelson. 2017. "The Effect of Large Monetary Incentives on Survey Completion: Evidence from a Randomized Experiment with the Survey of Consumer Finances." Public Opinion Quarterly 81(3): 736-747. Doi: https://doi.org/10.1093/poq/nfx006. 
Lillard, Lee, James P. Smith, and Finis Welch. 1986. "What do we really know about wages? The importance of nonreporting and census imputation." Journal of Political Economy 94, no. 3, Part 1: 489-506. Doi: https://doi.org/10.1086/261386.

National Research Council. 2009. Reengineering the Survey of Income and Program Participation. Constance F. Citro and John Karl Scholz, eds. Committee on National Statistics, Division of Behavioral and Social Sciences Education. Washington, DC: The National Academies Press.

U.S. Census Bureau. 2016. Survey of Income and Program Participation 2014 Panel Users' Guide. Washington, D.C., U.S.A. Available at: https://www.census.gov/programssurveys/sipp/guidance/users-guide.html. (accessed April 2019).

U.S. Census Bureau. 2017. Wealth, Asset Ownership, \& Debt of Households Detailed Tables: 2013. Washington, D.C. U.S.A. Available at: https://www.census.gov/topics/ income-poverty/wealth/data/tables.html. (accessed April 2019).

Watson, D., L.A. Clark, and A. Tellegen. 1998. "Development and Validation of Brief Measures of Positive and Negative Affect: the PANAS scales." Journal of Personality and Social Psychology 54(6): 1063-1070. Doi: http://doi.apa.org/journals/psp/54/6/ 1063.html.

Westra, A., M. Sundukchi, and T. Mattingly. 2015. "Designing a Multipurpose Longitudinal Incentives Experiment for the Survey of Income and Program Participation." In Proceedings of the 2015 Federal Committee on Statistical Methodology (FCSM) Research Conference, December 1-3, 2015. Washington, DC: Federal Committee on Statistical Methodology. Available at: https://s3.amazonaws. com/sitesusa/wp-content/uploads/sites/242/2016/03/E3_Westra_2015FCSM.pdf. (accessed April 2019).

Yan, T., R. Curtin, and M. Jans. 2010. "Trends in Income Nonresponse Over Two Decades." Journal of Official Statistics 26(1): 145-164. Available at: https://www.scb. se/contentassets/ca21efb41fee47d293bbee5bf7be7fb3/trends-in-income-nonresponseover-two-decades.pdf. (accessed April 2019).

Received April 2018

Revised November 2018

Accepted December 2018 